\title{
Effects of inorganic salts on biomass production, cell wall components, and bioethanol production in Nicotiana tabacum
}

\author{
Seon Jeong Sim·Seong Hyeon Yong $\cdot$ Hak Gon Kim $\cdot$ Myung Suk Choi $\cdot$ Pil Son Choi
}

Received: 29 September 2021 / Revised: 7 October 2021 / Accepted: 7 October 2021

(c) Korean Society for Plant Biotechnology

\begin{abstract}
The development of bioenergy through biomass has gained importance due to the increasing rates of fossil fuel depletion. Biomass is important to increase the productivity of bioethanol, and production of biomass with high biomass productivity, low lignin content, and high cellulose content is also important in this regard. Inorganic salts are important in the cultivation of biomass crops for the production of biomass with desirable characteristics. In this study, the roles of various inorganic salts in biomass and bioethanol production were investigated using an in vitro tobacco culture system. The inorganic salts evaluated in this study showed dramatic effects on tobacco plant growth. For example, $\mathrm{H}_{2} \mathrm{PO}_{4}$ substantially improved plant growth and the root/shoot $(\mathrm{R} / \mathrm{S})$ ratio. The chemical compositions of tobacco plants grown in media after removal of various inorganic salts also showed significant differences; for example, lignin content was high after $\mathrm{Mg}^{2+}$ removal treatment and low after $\mathrm{K}^{+}$treatment and $\mathrm{H}_{2} \mathrm{PO}_{4}$ removal treatment. On the other hand, $\mathrm{NO}_{3}^{-}$ and $\mathrm{H}_{2} \mathrm{PO}_{4}$ treatments yielded the highest cellulose content, while enzymatic hydrolysis yielded the highest
\end{abstract}

${ }^{\dagger}$ These authors contributed equally to this paper (co-corresponding authors).

S. J. Sim $\cdot$ H. G. Kim

Forest Research Department, Gyeongsangnam-do Forest Environment Research Institute, Jinju, 52615, Korea

S. H. Yong $\cdot$ Myung Suk Choi

Institute of Agriculture and Life Science, Gyeongsang National University, Jinju, Gyeongnam, 52828, South Korea

M. S. Choi $^{\dagger}(\bowtie)$

Division of Environmental Forest Science, Gyeongsang National University, Jinju, 52828, Republic of Korea

e-mail: mschoi@gnu.ac.kr

P. S. $\mathrm{Choi}^{\dagger}(\square)$

Department of Medicinal Plant Resources, Nambu University, Wealkye-dong, Gwangsan-gu, Gwangju 506706, Korea e-mail: cps6546@hanmail.net glucose concentration ratio $24 \mathrm{~h}$ after $\mathrm{NH}_{4}^{+}$removal treatment. The ethanol productivity after $\mathrm{H}_{2} \mathrm{PO}_{4}$ removal treatment was $3.95 \%(\mathrm{w} / \mathrm{v}) 24 \mathrm{~h}$ after fermentation and $3.75 \%(\mathrm{w} / \mathrm{v})$ after $36 \mathrm{~h}$. These results can be used as the basis for producing high-quality biomass for future bioethanol production.

Keywords Enzymatic hydrolysis, Fermentation, Inorganic salts, in vitro culture, Nicotiana tabacum L.

\section{Introduction}

This is because lignocellulosic biomass is non-edible, can be continuously reproduced, and is environmentally friendly because it does not emit greenhouse gases during production and use (Chandel et al. 2018). It is estimated that about 130 gallons of ethanol can be produced from 1.3 ton of biomass (Carroll et al. 2009).

Lignocellulosic biomass is mainly composed of cellulose, hemicellulose, and lignin, making it difficult for enzyme hydrolysation. That is why some pretreatment steps are essential to alter the physical and/or chemical structure of lignocellulosic biomass and easily convert polysaccharides into fermentable sugars, making cellulose more accessible (Kumar and Sharma 2017).

To effectively use lignocellulosic biomass, structural factors representing cellulose specific surface area, cellulose crystallinity, degree of polymerization, pore size and volume, and chemical factors related to the composition and content of lignin, hemicellulose, and acetyl groups must be considered (Zoghlami and Paës 2019).

Biomass is very important as a raw material for bioenergy, but the chemical composition of biomass is also important. Lignin imparts water resistance, firmness, and mechanical strength to the secondary cell wall, but interferes with the saccharification of cellulose. Lignin imparts water resistance, firmness and mechanical strength to the secondary cell 
wall, but interferes with the saccharification of cellulose or xylan. Lignin is given a water-resistance, durability and mechanical strength of the second cell wall, but hinders danghwaeul of cellulose or xylan. Therefore, a pretreatment process to remove lignin is required, and this process requires a lot of cost and time (Simmons et al. 2010).

The most ideal feedstock is one with a low lignin content and a high content of cellulose (Mandre (2002). However, these plant cell wall compounds are greatly affected by the cultivation environment. Soil nutrients must be carefully considered for high biomass production of bioenergy crops (Dimitriou and Rutz 2015). Plant growth is usually able to produce the most biomass in soil that contains a balanced amount of inorganic salts. Also, nutrients composition can cause a change in the content of lignin and other secondary metabolites in plants (Chapin 1991). The factors that can alter inorganic salts in plants may also affect the lignification process. However, the role of the inorganic salts in lignification is still not clear. The regulation of the supply of inorganic salts in plants may be one of the most easily practicable ways of directing the biosynthesis of lignin and other compounds in plants.

The lignocellulosic biomass is mainly composed of cellulose, hemicelluloses, and lignin, along with smaller amounts of pectin, protein and ash (Jørgensen et al. 2007). Pretreatment has been viewed as one of the most important and expensive steps in releasing sugars from hemicelluloses and cellulose (Kadam et al. 2008). Removing lignin and hemicelluloses, the reduction of cellulose crystallinity and the increase of porosity during the pretreatment processes can significantly improve the enzymatic hydrolysis of cellulose contained in the lignocellulosic material (Singh and Chen 2008).

The chemical and physical properties of the lignocellulosic biomass can affect the choice and efficiency of the biomass conversion process (Tillman 2000). However, very few studies have been made on the effects of inorganic salts on these lignocellulosic biomass. Especially in the field, these studies have been difficult to create a uniform environment. The purpose of this study is to evaluate the effect of inorganic salts on plant growth and biosynthesis of major compounds using the in vitro culture system of tobacco, a model plant, and further investigate the bioethanol production efficiency of each inorganic salts.

\section{Materials and Methods}

Plant materials and preparation of medium with revised inorganic salts

The plant material for $N$. tabacum was provided by the National Institute of Forest Science. In vitro plants were passaged every 4 weeks in $1 / 2 \mathrm{MS}$ (Murashige and Skoog 1962) medium and cultured for 1 year. Plants used in the experiment were cultured for 6 weeks at a size of $5 \mathrm{~cm}$ in the early stage of culture Cultured plants were harvested after 14, 28, 42 and 56 days of culture, respectively, and their growth characteristics were investigated. We used a plant with a size of $15 \mathrm{~cm}$ as the sample for chemical analysis.

The medium was prepared to investigate the effects of inorganic salts on biomass production, the major components of the biosynthesis of plants and cell walls and the bioethanol production of $N$. tabacum. In addition, in a previous study, it was found that $1 / 2 \mathrm{MS}$ medium is suitable for culture, and the concentration used in this study was determined within this range.

The $1 / 2$ MS solid medium was prepared by removing large amounts and trace inorganic salts. $\mathrm{T} 1$ is a basic medium composition for MS, and T2 to T8 are treatments in which nitrogen sources (ammonium and nitrate), potassium, calcium, magnesium, and iron are removed. Each treatment contains all of the other ingredients except inorganic salts. The revised medium was adjusted to $\mathrm{pH}$ 5.8 after the addition of $0.7 \%$ agar without the addition of growth regulators. The $\mathrm{pH}$ of the eight experimental treatments used in this study was $4.3 \sim 5.2$. Therefore, it was neutralized with $1 \mathrm{~N} \mathrm{HCl}$ to reach an optimum $\mathrm{pH}$ of 5.8 .

National Renewable Energy Laboratory (NREL Golden, CO) analytical methods for biomass (NREL 1996), carbohydrates, lignin (acid-insoluble, acid soluble), extractives and the ash content of raw materials were determined according to NREL procedures (Sluiter et al. 2008). Reagents used for all analysis were Sigma-Aldrich's extra pure grade.

In vitro culture in medium revised with inorganic salts

Surface-sterilized $N$. tabacum shoots were cut into $2 \sim 3 \mathrm{~cm}$ pieces and cultured in $1 / 2$ MS solid medium. In vitro plantlets were further placed in culture vessels containing $50 \mathrm{~mL}$ of $1 / 2 \mathrm{MS}$ basal medium containing sucrose $(3 \%$ $\mathrm{w} / \mathrm{v})$. All cultures were maintained under a $16 \mathrm{~h}$ light $/ 8 \mathrm{~h}$ dark photoperiod in a growth chamber fitted with a cool fluorescent light emitting $25 \mu \mathrm{mol} \mathrm{m} \mathrm{m}^{-2}$ of photosynthetically active radiation (PAR).

To determine variations in biomass by inorganic salt treatments, individual shoots were cultured on the revised 
Table 1 Inorganic salt compositions of the media used for in vitro culture

\begin{tabular}{cccccccc}
\hline \multirow{2}{*}{ Treatment } & \multicolumn{7}{c}{ Medium inorganic salt $(\mathrm{mM})$} \\
\cline { 2 - 7 } & $\mathrm{NH}_{4}{ }^{+}$ & $\mathrm{NO}_{3}{ }^{-}$ & $\mathrm{H}_{2} \mathrm{PO}_{4}^{-}$ & $\mathrm{K}^{+}$ & $\mathrm{Ca}^{2+}$ & $\mathrm{Mg}^{2+}$ & 0.751 \\
$\mathrm{~T} 1$ & 0.515 & 0.985 & 0.031 & 0.503 & 0.748 & 0.010 \\
$\mathrm{~T} 2$ & 0 & 0.470 & 0.031 & 0.503 & 0.748 & 0.751 & 0.010 \\
$\mathrm{~T} 3$ & 0 & 0 & 0.031 & 0.033 & 0.748 & 0.751 & 0.010 \\
$\mathrm{~T} 4$ & 0.515 & 0.985 & 0 & 0.472 & 0.748 & 0.751 & 0.010 \\
$\mathrm{~T} 5$ & 0.515 & 0.515 & 0 & 0 & 0.748 & 0.751 & 0.010 \\
$\mathrm{~T} 6$ & 0.515 & 0.985 & 0.031 & 0.503 & 0 & 0.751 & 0.010 \\
$\mathrm{~T} 7$ & 0.515 & 0.985 & 0.031 & 0.503 & 0.748 & 0.010 \\
$\mathrm{~T} 8$ & 0.515 & 0.985 & 0.031 & 0.503 & 0.748 & 0.751 & 0 \\
\hline
\end{tabular}

1/2 MS solid medium without any plant growth regulators for 8 weeks. Shoot growth and biosynthesis of lignin, cellulose and low molecular weight compounds were investigated by culturing plants in $1 / 2 \mathrm{MS}$ medium except for each inorganic salt. (Table 1).

After 8 weeks of culture, the number of shoots and leaves, wilting rate, fresh and dry biomass weight of above and underground, and root/shoot ratio were investigated. The chlorophyll content of plant leaves was measured using a Soil Plants Analysis Development (Soil Plants Analysis Development) 502 portable chlorophyll meter (Minolta Co., Ltd., Japan). The SPAD values were repeatedly taken at the center of the leaves throughout the experiments.

\section{Lignin biosynthesis assay}

For the histochemical analysis of lignin in biomass, the lignin of the cultured biomass was stained with Wiesner reagents (Geiger and Fuggerer 1979). Wiesner's reagent states that under acidic conditions, phloroglucinol produces a red-pink product with the cinnamaldehyde group present primarily in lignin. The shoots were sectioned with a sharp razor blade, and sections were placed in $2 \%$ phloroglucinol in $95 \%$ ethanol for $5 \mathrm{~min}$ and mounted in $6 \mathrm{n}$ $\mathrm{HCl}$. The lignin was identified as a red color when observed under a light microscope.

Chemical composition of biomass obtained in different media

To determine the chemical composition of biomass, National Renewable Energy Laboratory analytical methods (NREL 1996) were applied. The shoot tissue (dry weight $100 \mathrm{~g}$ ) was cut into pieces and vacuum-dried at $70^{\circ} \mathrm{C}$ for 24 hours. Thereafter, the sample was extracted with ethanol for 3 hours with a Soxhlet extractor and then vacuum dried at $105^{\circ} \mathrm{C}$. for 48 hours. The lignin and holocellulose contents were measured after delignification with $\mathrm{NaClO}_{2}$ (Wise et al. 1946). $2.5 \mathrm{~g}$ of the degreased sample was repeatedly treated with $1 \mathrm{~g}$ of $\mathrm{NaClO}_{2}$ in $0.2 \mathrm{~mL}$ of diluted acetic acid solution) three times, and then reacted at $70^{\circ} \mathrm{C}$ for 1 hour. The delignified product, holocellulose, was filtered, washed with distilled water, dried at $105^{\circ} \mathrm{C}$ for $48 \mathrm{~h}$ in vacuo and weighed.

The $\alpha$-cellulose content was determined as the insoluble residue in the $\mathrm{NaOH}(17.5 \%)$ aqueous solution. A flask containing a $1 \mathrm{~g}$ sample of the holocellulose obtained according to the process above was dissolved in $\mathrm{NaOH}$. The mixture was stirred for $30 \mathrm{~min}$ at $20^{\circ} \mathrm{C}$, and $25 \mathrm{ml}$ of distilled water was then added to the mixture. After 5 min, the residue was filtrated, and then supplemented with $40 \mathrm{ml}$ of $10 \%$ acetic acid and allowed to stand. The resulting residue was collected by filtration and washed with $1 \mathrm{~L}$ of boiling water. The residue that contained $\alpha$ cellulose was finally dried at $105^{\circ} \mathrm{C}$ for $48 \mathrm{~h}$ in vacuo and weighed. The contents of lignin, holocellulose, and $\alpha$ cellulose in the original $N$. tabacum chips were calculated as dry weights relative to the original plant mass. The $\alpha$ cellulose content was quantified as cellulose. The hemicellulose content of the biomass was determined by the subtraction of the $\alpha$-cellulose from that of holocellulose. To observe cellulose using field emission scanning electron microscopy (Fe-SEM) analysis, delignificated tissues were air-dried before being used for microscopic examination. The $\alpha$-cellulose solids were transferred to carbon tape on copper stubs and sputtered with gold (10 mA and 300s) using a high-resolution sputter coater (Agar Scientific Ltd, USA). Fe-SEM investigations were carried out with a Philips XL30 S-FEG Microscope (Netherlands) operated at $15 \mathrm{kV}$, Magnification 200x or 300x. Images were acquired with Quartz PCI Version 4 software (Hitachi high-technologies, Japan).

Enzymatic hydrolysis and ethanol fermentation

Enzymatic hydrolysis was carried out on the non-delignified 
raw material. For enzymatic hydrolysis, $1 \mathrm{~g}$ of extractive-free dry biomass was finely ground and transferred to a $250 \mathrm{~mL}$ Erlenmeyer flask containing $50 \mathrm{~mL}$ of $0.1 \mathrm{M}$ sodium citrate buffer ( $\mathrm{pH} 4.8$ ). Next, appropriate amounts of cellulase (58.56 FPUg-1) and an equal amount of $\beta$-glucosidase (24.2 FBG/g) were added. The flask was placed in a shaking incubator (IS-97IR, Jeio-Tech Co. Korea) and maintained at $50^{\circ} \mathrm{C}$ for $36 \mathrm{~h}(150 \mathrm{rpm})$. The released glucose in the medium was analyzed with a mutarotase-GOD method employing a glucose CII-test kit (Wako Pure Chemical Industrie Ltd.) after the heat-denaturing of enzymes $\left(100^{\circ} \mathrm{C}\right.$ for $10 \mathrm{~min}$ ). The enzymes used for enzymatic hydrolysis were Celluclast 1.5 L (Novo Co. Denmark), cellulase from Trichoderma reesei and Viscozyme L (Novo Co. Denmark) as $\beta$-glucosidase.

Regarding fermentation, Saccharomyces cerevisiae KCCM 11215 was used for the ethanol fermentation study. The inoculum required for fermentation was developed in YM (Yeast and Mold) liquid medium (yeast extract $3 \mathrm{~g} / \mathrm{L}$, malt extract $3 \mathrm{~g} / \mathrm{L}$, peptone $5 \mathrm{~g} / \mathrm{L}$ and dextrose $10 \mathrm{~g} / \mathrm{L}$ ). Later, an inoculum $\left(1.5 \times 10^{8}\right.$ cells $\left./ \mathrm{mL}\right)$ was seeded to fermentation broth $(5 \% \mathrm{v} / \mathrm{v})$.

Ethanol production was quantified by a gas chromatograph (GC) (Agilent Technologies). The fermentation broth obtained after $36 \mathrm{~h}$ was filtered through a $0.2 \mu \mathrm{m}$ filter before GC analysis to remove any coarse particles (Krishna and Chowdary 2000) for alcohol estimation. The GC was equipped with an HP-FFAP column of $30 \mathrm{~m}$ with an ID $0.25 \mathrm{~mm}$. The detector and injection port were maintained at $200^{\circ} \mathrm{C}$. The combustion gas was a mixture of hydrogen and air, and nitrogen was used as a carrier gas at a flow rate of $40 \mathrm{~mL} / \mathrm{min}$. The quantification of ethanol by the GC was obtained by comparison with a standard curve generated based on the detector response to known amounts of alcohol.

Statistical analysis

A one-way ANOVA was used to test for differences in $N$. tabacum growth. Means were separated by Duncan's multiple range test $(P=0.05)$. Mean values were expressed as standard error $( \pm$ SE). All data sets were subjected to analysis with the SPSS package (SPSS, Inc. Chicago, IL, USA).

\section{Results}

Effect of inorganic salts on shoot growth

Inorganic salt had a dramatic effect on tobacco plant growth (Table 2). The control without changing the inorganic salt component had the best growth. After 8 weeks of culture, the sprout growth of tobacco in the control was $12.45 \mathrm{~cm}$. The treatments that showed the best growth in the inorganic salt removal medium was the $\mathrm{Ca}^{+}$treatment, followed by $\mathrm{Fe}^{3+}$ and $\mathrm{Mg}^{2+}$. On the other hand, the treatment that most inhibited the growth of tobacco shoots was $\mathrm{H}_{2} \mathrm{PO}_{4}$, and almost no growth was achieved. In addition, treatments that inhibited growth were in the order of $\mathrm{NH}_{4}{ }^{+}, \mathrm{K}^{+}$, and $\mathrm{NO}_{3}^{-}$.

Table 2 Influence of various inorganic salt treatments on plants

\begin{tabular}{|c|c|c|c|c|c|c|c|c|}
\hline \multirow{2}{*}{ Treatment } & \multicolumn{3}{|c|}{ Shoot growth } & \multirow{2}{*}{$\begin{array}{c}\text { Withering } \\
\text { rate }\end{array}$} & \multicolumn{2}{|c|}{ Leaf appearance } & \multirow{2}{*}{$\begin{array}{c}\text { SPAD } \\
\text { chlorophyll } \\
\text { value }\end{array}$} & \multirow{2}{*}{$\begin{array}{c}\text { Root } \\
\text { growthb } \\
(\mathrm{cm})\end{array}$} \\
\hline & Shoot growth & $\begin{array}{c}\text { No. of } \\
\text { shoots/explants }^{\mathrm{b}}\end{array}$ & $\begin{array}{l}\text { No. of } \\
\text { leaves }\end{array}$ & & Leaf length & $\begin{array}{l}\text { Leaf width } \\
\text { (cm) }\end{array}$ & & \\
\hline $\mathrm{T} 1$ & $12.64 \pm 0.23 \mathrm{a}$ & $1.00 \pm 0.00$ & $19.8 \pm 1.08 \mathrm{a}$ & $1 \pm 0.61 \mathrm{~b}$ & $3.31 \pm 0.52 \mathrm{~d}$ & $2.34 \pm 0.34 \mathrm{~b}$ & $31.83 \pm 5.08 \mathrm{a}$ & $6.91 \pm 0.93 \mathrm{bc}$ \\
\hline $\mathrm{T} 2$ & $5.74 \pm 1.08 \mathrm{~d}$ & $1.20 \pm 0.22$ & $12.8 \pm 0.89 \mathrm{~d}$ & $1.4 \pm 0.57 \mathrm{~b}$ & $3.88 \pm 0.14 \mathrm{~cd}$ & $2.33 \pm 0.09 b$ & $23.92 \pm 5.93 b$ & $9.13 \pm 2.76 \mathrm{ab}$ \\
\hline $\mathrm{T} 3$ & $8.11 \pm 1.65 c$ & $1.40 \pm 0.45$ & $16.75 \pm 1.31 \mathrm{c}$ & $0.75 \pm 0.48 b$ & $4.33 \pm 0.5 b c$ & $2.63 \pm 0.23 b$ & $15.8 \pm 0.99 \mathrm{c}$ & $3.46 \pm 0.26 \mathrm{~d}$ \\
\hline $\mathrm{T} 4$ & $1.88 \pm 0.21 \mathrm{e}$ & $1.00 \pm 0.00$ & $7 \pm 1 \mathrm{e}$ & $4.6 \pm 0.76 \mathrm{a}$ & $2.02 \pm 0.08 \mathrm{e}$ & $1.32 \pm 0.14 \mathrm{c}$ & $2.23 \pm 0.98 \mathrm{~d}$ & $9.3 \pm 1.25 \mathrm{a}$ \\
\hline $\mathrm{T} 5$ & $7.03 \pm 0.98 \mathrm{c}$ & $1.40 \pm 0.27$ & $18.2 \pm 0.96 \mathrm{bc}$ & $6.6 \pm 1.3 \mathrm{a}$ & $3.62 \pm 0.12 \mathrm{~d}$ & $2.44 \pm 0.06 \mathrm{~b}$ & $17.9 \pm 3.75 b c$ & $6.64 \pm 0.48 \mathrm{c}$ \\
\hline $\mathrm{T} 6$ & $10.75 \pm 0.56 b$ & $1.00 \pm 0.00$ & $17.2 \pm 2.41 \mathrm{c}$ & $5.2 \pm 2.54 \mathrm{a}$ & $5.66 \pm 0.31 \mathrm{a}$ & $3.44 \pm 0.31 \mathrm{a}$ & $18.03 \pm 4.41 b c$ & $7.46 \pm 0.33 \mathrm{abc}$ \\
\hline $\mathrm{T} 7$ & $10.6 \pm 0.58 b$ & $1.00 \pm 0.00$ & $16 \pm 1.47 \mathrm{c}$ & $4.75 \pm 1.89 \mathrm{a}$ & $4.51 \pm 0.54 b c$ & $3.11 \pm 0.25 \mathrm{a}$ & $20.05 \pm 3.67 b c$ & $6.89 \pm 1.33 b c$ \\
\hline $\mathrm{T} 8$ & $10.52 \pm 1.31 b$ & $1.00 \pm 0.00$ & $17.33 \pm 1.26 b c$ & $1.33 \pm 0.58 b$ & $4.78 \pm 0.36 b$ & $3.37 \pm 0.24 \mathrm{a}$ & $31.73 \pm 2.39 \mathrm{a}$ & $7.21 \pm 0.7 \mathrm{abc}$ \\
\hline
\end{tabular}

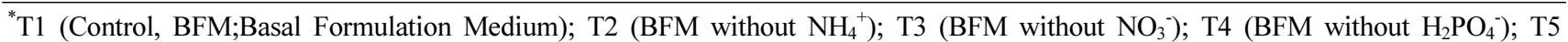
$\left(\mathrm{BFM}\right.$ without $\left.\mathrm{K}^{+}\right)$; T6 (BFM without $\left.\mathrm{Ca}^{2+}\right)$; T7 (BFM without $\mathrm{Mg}^{2+}$ ); T8 (BFM without $\mathrm{Fe}^{3+}$ ). ${ }^{* *}$ Each value represents the mean \pm standard error of at least three replicates. 
Appearance of plant and lateral shoot induction

Inorganic salts influenced the formation of multiple shoots of $N$. tabacum (Table 2). Multiple shoot was highly induced in $\mathrm{NO}_{3}^{-}$and $\mathrm{K}^{+}$removal treatments. The $1 / 2 \mathrm{MS}$ medium from which the $\mathrm{NO}_{3}^{-}$component was removed produced a significantly higher number of shoots than the other media tested. However, other than the control, nitrogen source and $\mathrm{K}^{+}$removal treatment, multiple shoots were not induced.

Effect of inorganic salts on leaf appearance

Inorganic salt affects the development and appearance of leaves (Table 2). Plant leaves in the inorganic salt removed medium had fewer leaves than in the control medium $(1 / 2$ MS basal medium) without inorganic salt adjustment. The number of leaves was the highest in the medium without $\mathrm{K}^{+}$, but the number of leaves was the least in the in the medium without $\mathrm{H}_{2} \mathrm{PO}_{4}^{-}$. However, plant leaves cultured in $\mathrm{Ca}^{2+}$ and $\mathrm{Fe}^{3+}$ removal media appeared longer, although transient. Leaf length had no significant effect except for $\mathrm{H}_{2} \mathrm{PO}_{4}{ }^{-}$removal media. However, plant leaves cultured in $\mathrm{Ca}^{2+}$ and $\mathrm{Fe}^{3+}$ removal media appeared longer, although transient.

Leaf width also affected the inorganic salt removal medium. Leaf width also showed similar pattern to leaf length. Leaf width was very small in $\mathrm{Ca}^{2+}$ removal medium but had no significant effect in other treatments. Rather, the leaf width was larger in the $\mathrm{Ca}^{2+}, \mathrm{Mg}^{2+}$ and $\mathrm{Fe}^{3+}$ removal media.

Leaves cultivated in the inorganic salt removed medium were observed to wilt over time. In particular, in the treatment of removing $\mathrm{K}^{+}$and $\mathrm{Ca}^{2+}$, the wilt rate of plants was high, but in the treatment of removing $\mathrm{NO}_{3}$, leaf wilt was less. At the tips and edges of the leaves, mainly after yellowing of the leaves, necrosis was observed (Table 2).

The chlorophyll content of the leaves also had a large amount depending on the type of inorganic salt. The measured SPAD value was the lowest in the $\mathrm{NO}_{3}{ }^{-}$removal treatment, followed by $\mathrm{H}_{2} \mathrm{PO}_{4}^{-}$and $\mathrm{K}^{+}$. However, the SPAD value of leaves was higher than that of the control treatment in the $\mathrm{Ca}^{2+}$ removal treatment, indicating that $\mathrm{Ca}^{2+}$ did not significantly affect the chlorophyll content. In addition, it was found that the SPAD value of the leaf was not significantly affected by $\mathrm{Mg}^{2+}$ and $\mathrm{Fe}^{3+}$ ions.

Effect of inorganic salts on root growth and $\mathrm{S} / \mathrm{R}$ ratio

Root growth was different according to the type of inorganic salt (Table 2). In the control, root formation occurred within 56 days, and $100 \%$ roots occurred in the inorganic salt removal medium (data not shown). Root induction and growth also affected according to inorganic salt kinds. It was found that $\mathrm{K}^{+}$and $\mathrm{Mg}^{2+}$ had a great influence on root development and growth.

Effect of inorganic salts on the aboveground and underground biomass production

Changes in biomass production of plants cultured for 8 weeks in a medium from which inorganic salts were removed were investigated (Table 3). Inorganic salts have affected the biomass production of tobacco cultured in vitro. Overall, except for the $\mathrm{Fe}^{3+}$-removed treatments, the

Table 3 Effect of inorganic salts on biomass production in N. tabacum

\begin{tabular}{|c|c|c|c|c|c|c|c|}
\hline \multirow{2}{*}{ Treatment $^{\mathrm{a}}$} & \multicolumn{3}{|c|}{$\begin{array}{l}\text { Fresh mass production } \\
\qquad(\mathrm{g} / \text { plant })\end{array}$} & \multicolumn{3}{|c|}{$\begin{array}{l}\text { Dry mass production } \\
(\mathrm{g} / \text { plant })\end{array}$} & \multirow{2}{*}{$\begin{array}{l}\mathrm{R} / \mathrm{S} \\
\text { ratio }^{\mathrm{b}}\end{array}$} \\
\hline & $\begin{array}{l}\text { Aboveground } \\
\text { part }\end{array}$ & $\begin{array}{l}\text { Underground } \\
\text { part }\end{array}$ & Total & $\begin{array}{c}\text { Aboveground } \\
\text { part }\end{array}$ & $\begin{array}{l}\text { Underground } \\
\text { part }\end{array}$ & Total & \\
\hline $\mathrm{T} 1$ & 5.40 & 0.47 & 5.87 & 0.29 & 0.04 & 0.33 & 0.14 \\
\hline $\mathrm{T} 2$ & 2.45 & 0.59 & 3.04 & 0.11 & 0.04 & 0.15 & 0.36 \\
\hline $\mathrm{T} 3$ & 2.79 & 0.35 & 3.14 & 0.27 & 0.02 & 0.29 & 0.08 \\
\hline $\mathrm{T} 4$ & 0.45 & 1.37 & 1.82 & 0.07 & 0.09 & 0.16 & 1.29 \\
\hline $\mathrm{T} 5$ & 2.55 & 1.01 & 3.56 & 0.38 & 0.08 & 0.46 & 0.21 \\
\hline T6 & 4.87 & 1.50 & 6.37 & 0.41 & 0.13 & 0.54 & 0.32 \\
\hline $\mathrm{T} 7$ & 4.55 & 1.83 & 6.38 & 0.41 & 0.13 & 0.54 & 0.32 \\
\hline $\mathrm{T} 8$ & 5.89 & 1.85 & 7.74 & 0.41 & 0.15 & 0.56 & 0.36 \\
\hline
\end{tabular}

${ }^{\mathrm{a}} \mathrm{T} 1$ (Control, BFM); T2 (BFM without $\left.\mathrm{NH}_{4}^{+}\right)$; T3 (BFM without $\left.\mathrm{NO}_{3}^{-}\right)$; T4 (BFM without $\left.\mathrm{H}_{2} \mathrm{PO}^{4-}\right)$; T5 (BFM without $\left.\mathrm{K}^{+}\right)$; T6 (BFM without $\left.\mathrm{Ca}^{2+}\right)$; $\mathrm{T} 7\left(\mathrm{BFM}\right.$ without $\left.\mathrm{Mg}^{2+}\right)$; T8 (BFM without $\mathrm{Fe}^{3+}$ ).

${ }^{\mathrm{b}} \mathrm{R} / \mathrm{S}$ ratio $=$ Root dry weight $(\mathrm{g}) /$ Shoot dry weight $(\mathrm{g})$. 


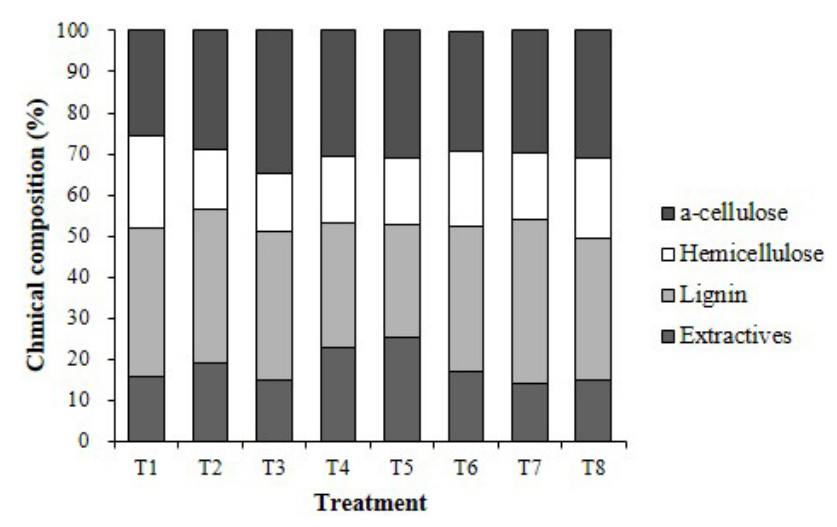

Fig. 1 Chemical composition (\%) based on inorganic salt treatment of in vitro cultivated biomass. T1 (Control, BFM); T2 (BFM without $\mathrm{NH}_{4}{ }^{+}$); T3 (BFM without $\mathrm{NO}_{3}{ }^{-}$); T4 (BFM without $\left.\mathrm{H}_{2} \mathrm{PO}_{4}^{-}\right)$; $\mathrm{T} 5$ (BFM without $\mathrm{K}^{+}$); T6 (BFM without $\mathrm{Ca}^{2+}$ ); $\mathrm{T} 7\left(\mathrm{BFM}\right.$ without $\mathrm{Mg}^{2+}$ ); and $\mathrm{T} 8$ (BFM without $\mathrm{Fe}^{3+}$ )

aboveground biomass productivity of tobacco decreased. The treatment with the lowest biomass production on the aboveground was the $\mathrm{H}_{2} \mathrm{PO}_{4}^{-}$removal treatment, and the production was very low in the $\mathrm{NH}_{4}^{+}$and $\mathrm{NO}_{3}^{-}$removal treatment. The biomass production in the underground was different from that of the above-ground (Table 3). The production of biomass underground increased in other treatments except for the medium from which $\mathrm{NO}_{3}^{-}$was removed. In particular, the $\mathrm{Mg}^{2+}$ and $\mathrm{Fe}^{3+}$ removal treatments produced 3.9 times that of the control treatment. The standard biomass production during drying also showed a similar trend to that of fresh.

In addition, the ratio of the amount of biomass in the aboveground and the amount of biomass in the basement was different in the inorganic salt treatment (Table 3). The $\mathrm{R} / \mathrm{S}$ ratio of the control treatment was 0.13 , but the $\mathrm{R} / \mathrm{S}$ ratio was increased in all except for the $\mathrm{NO}_{3}^{-}$removal treatment. The treatment with the highest $\mathrm{R} / \mathrm{S}$ ratio was the treatment with $\mathrm{H}_{2} \mathrm{PO}_{4}^{-}$removal.

Effect of inorganic salts on the chemical composition

The chemical composition of tobacco plants grown in inorganic salt-free medium showed significant differences between treatments (Fig. 1). Extractive content varied from treatment to treatment. Treatment with the highest extractive content was $\mathrm{K}^{+}$, followed by $\mathrm{H}_{2} \mathrm{PO}_{4}^{-}, \mathrm{NH}^{4+}$, and $\mathrm{Ca}^{2+}$.

The lignin content also showed differences according to the inorganic salt (Fig. 1). The treatment with the lowest lignin content was the $\mathrm{K}^{+}$treatment, followed by the $\mathrm{H}_{2} \mathrm{PO}_{4}^{-}$ removal treatment.

Histochemical observation of lignin according to the inorganic salt treatment was performed (Fig. 2). Because
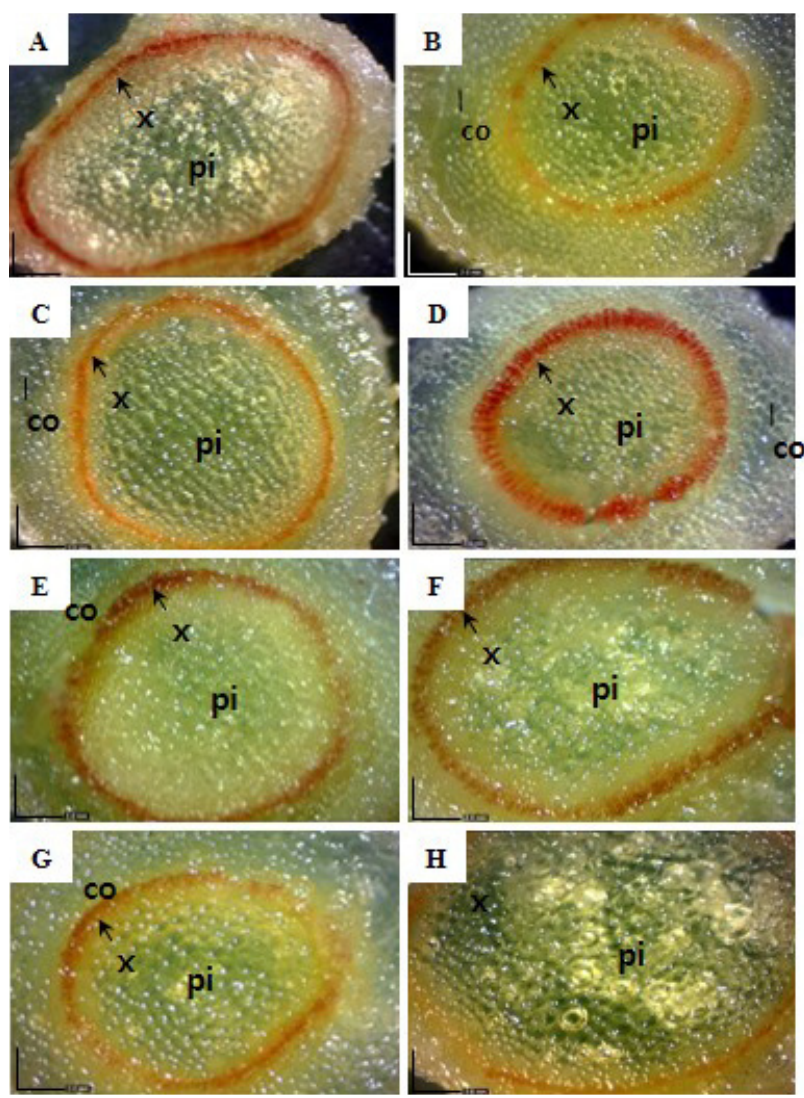

Fig. 2 Histochemical lignin (phloroglucinol-HCl) staining of shoot cross-sections from 8-week-old N. tabacum plantlets with Wiener (bar: $2 \mathrm{~mm}$ ). Lignin is stained red. Abbreviations: co, cortex; pi, pith; x, xylem. Magnification, x300. (A) T1 (Control, BFM); (B) T2 (BFM without $\mathrm{NH}_{4}^{+}$); (C) T3 (BFM without $\mathrm{NO}_{3}^{-}$); (D) $\mathrm{T} 4$ (BFM without $\mathrm{H}_{2} \mathrm{PO}_{4}^{-}$); (E) T5 (BFM without $\mathrm{K}^{+}$); (F) T6 (BFM without $\mathrm{Ca}^{2+}$ ); (G) T7 (BFM without $\mathrm{Mg}^{2+}$ ); and $(\mathrm{H}) \mathrm{T} 8\left(\mathrm{BFM}\right.$ without $\mathrm{Fe}^{3+}$ ).

Wiesner reagent gives only temporary visualization of color, images were recorded within $10 \mathrm{~min}$ of reagent application. To visualize the lignified tissues in 8 weeks-old plantlet shoots, cross section of middle was treated with the Wiesner (phloroglucinol-HCl) reagents. The presence of lignin was confirmed by phloroglucinol-HCl staining. The amount of lignin dyeing was different for each inorganic salt removal treatment. The staining area of lignin begins in the phloem fibers (pf) and in the neck (x). Among them, the most distinct treatments were the $\mathrm{H}_{2} \mathrm{PO}_{4}^{-}$removal treatments. However, the degree of occurrence between treatments was not significantly different.

Hemicellulose content also varied from treatment to treatment (Fig. 1). The hemicellulose content of the plants in the inorganic salt removal medium was $22.40 \%$, which was lower than that of the plants grown in the control medium. The treatment with the lowest hemicellulose content was $14.52 \%$ with $\mathrm{NO}^{3-}$, and the treatment with $\mathrm{NH}^{4+}$ and 


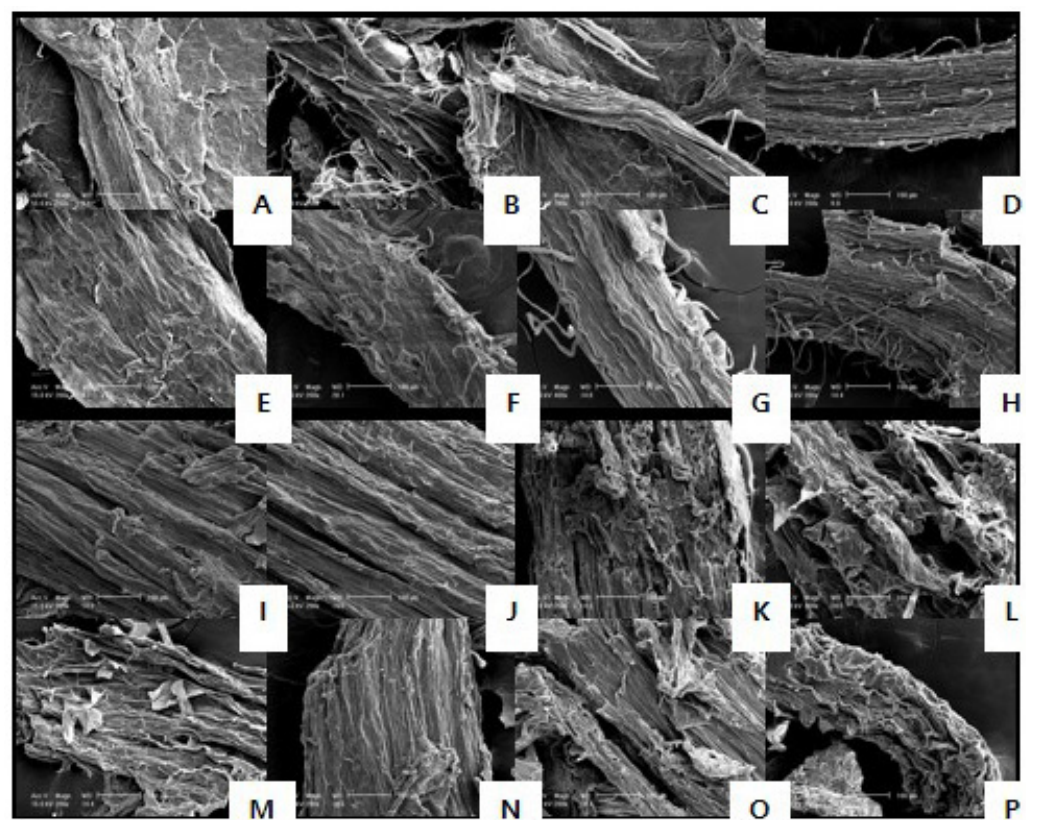

Fig. 3 Fe-SEM images after inorganic salt treatments of the dried alphacellulose of N. tabacum (I-P). (A and I) T1 (Control, BFM); (B and J) T2 (BFM without $\left.\mathrm{NH}_{4}^{+}\right)$; $(\mathrm{C}$ and $\mathrm{K}) \mathrm{T} 3\left(\mathrm{BFM}\right.$ without $\left.\mathrm{NO}_{3}{ }^{-}\right)$; (D and L) T4 (BFM without $\left.\mathrm{H}_{2} \mathrm{PO}_{4}{ }^{-}\right)$; (E and M) T5 (BFM without $\left.\mathrm{K}^{+}\right)$; $(\mathrm{F}$ and $\mathrm{N}) \mathrm{T} 6\left(\mathrm{BFM}\right.$ without $\left.\mathrm{Ca}^{2+}\right)$; $(\mathrm{G}$ and $\mathrm{O}) \mathrm{T} 7\left(\mathrm{BFM}\right.$ without $\left.\mathrm{Mg}^{2+}\right)$; and $(\mathrm{H}$ and $\mathrm{P}) \mathrm{T} 8\left(\mathrm{BFM}\right.$ without $\left.\mathrm{Fe}^{3+}\right)$.

$\mathrm{H}_{2} \mathrm{PO}_{4}^{-}$removal also had a low content. Among the inorganic salt removal treatments, the treatment with a low hemicellulose content was $\mathrm{Fe}^{3+}$.

The $\alpha$-cellulose content was also different according to the inorganic salt treatments (Fig. 1). The $\alpha$-cellulose content of plant varied from $25.71 \%$ to $34.63 \%$. It was found that the cellulose content of plants cultured in the treatment from which the inorganic salt was removed was increased compared to the control. Among them, the treatment with the highest cellulose content was $\mathrm{NO}^{3-}$ treatment, followed by $\mathrm{H}_{2} \mathrm{PO}_{4}^{-}$and $\mathrm{K}^{+}$treatment. To investigate the morphology of cellulose purified from plants cultured in an inorganic salt removal medium, it was analyzed by Fe-SEM (Fig. 3). Microscopic analysis helped to visualize clear surface morphological differences between $\alpha$-cellulose samples. It was found that cellulose microfibrils were exposed on the surface of the biomass. The SEM image suggested that the main component present in the original microcrystalline cellulose was coarse and condensed fibrils. Cellulose cultured in the inorganic salt removal medium was coarser. However, there was no significant difference in the structure of the cellulose of plants grown in each treatment group only by SEM analysis.

Effect of inorganic salts on enzymatic hydrolysis

As a result of enzymatic hydrolysis of plants grown in inorganic salt removal medium, it was found that the

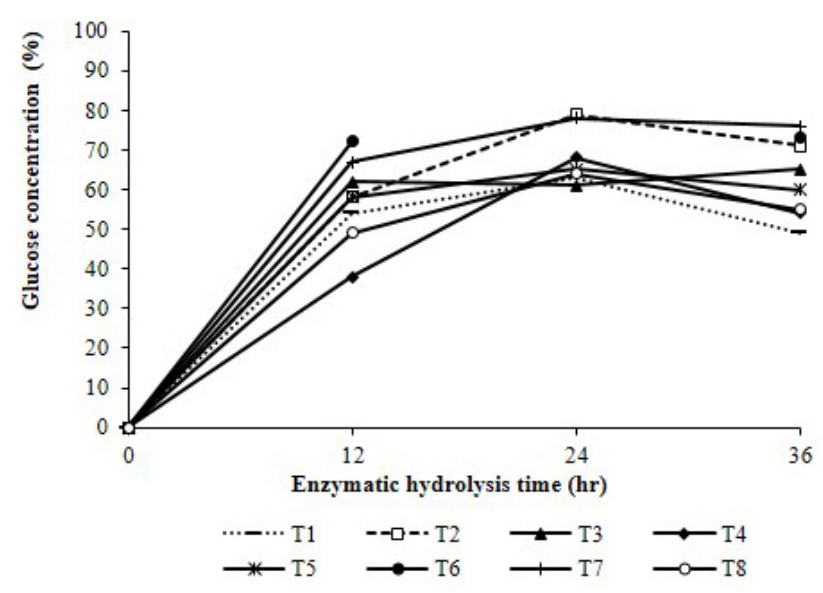

Fig. 4 Effect of time on enzymatic hydrolysis of $N$. tabacum after inorganic salt treatment Temperature, $50^{\circ} \mathrm{C}$; $\mathrm{pH} 4.8$; enzyme loading, 58.56 FPU $\cdot \mathrm{g}^{-1}$ of cellulose (Celluclast 1.5 L) and 24.2 FBG/g of $\beta$-glucosidase (Novozyme). T1 (Control, BFM); T2 (BFM without $\mathrm{NH}_{4}^{+}$); T3 (BFM without $\mathrm{NO}_{3}^{-}$); T4 (BFM without $\left.\mathrm{H}_{2} \mathrm{PO}_{4}^{-}\right)$; T5 (BFM without $\mathrm{K}^{+}$); T6 (BFM without $\mathrm{Ca}^{2+}$ ); T7 $\left(\mathrm{BFM}\right.$ without $\left.\mathrm{Mg}^{2+}\right)$; and $\mathrm{T} 8\left(\mathrm{BFM}\right.$ without $\mathrm{Fe}^{3+}$ ).

saccharification rate increased with time (Fig. 4). In addition, the saccharification rate showed a large difference according to the inorganic salt removal treatments. The treatment with the highest saccharification rate reached the highest concentration ratio of glucose after 24 hours of enzymatic hydrolysis for $\mathrm{NH}_{4}^{+}$removal treatment and $\mathrm{Mg}^{2+}$ removal tobacco treatment, respectively, $79 \%$ and $78 \%$. 


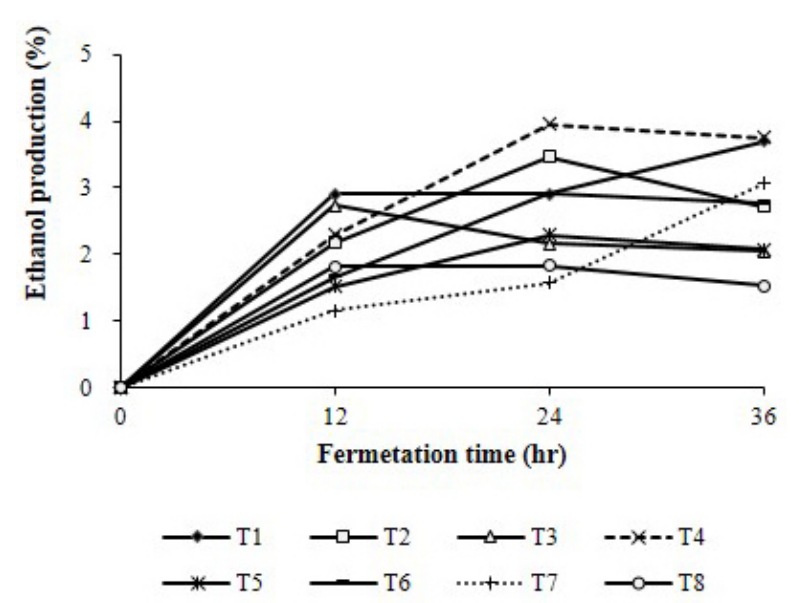

Fig. 5 Effect of time on ethanol production after treatment of $N$. tabacum with inorganic salts. Enzymatic saccharification was performed using 58.56 FPU of cellulose (Celluclast 1.5 L) and the cellulose proportion of $\beta$-glucosidase (Novozyme 188). T1 (Control, BFM); T2 (BFM without $\left.\mathrm{NH}_{4}{ }^{+}\right)$; $\mathrm{T} 3$ (BFM without $\mathrm{NO}_{3}^{-}$); T4 (BFM without $\mathrm{H}_{2} \mathrm{PO}_{4}^{-}$); T5 (BFM without $\mathrm{K}^{+}$); T6 (BFM without $\left.\mathrm{Ca}^{2+}\right)$; $\mathrm{T} 7\left(\mathrm{BFM}\right.$ without $\left.\mathrm{Mg}^{2+}\right)$; $\mathrm{T} 8\left(\mathrm{BFM}\right.$ without $\mathrm{Fe}^{3+}$ ).

Effect of inorganic salts on fermentation of enzymatic hydrolyzates

The fermentation process was carried out using glucose obtained by enzymatic hydrolysis. S. cerevisiae KCCM 1215 was also used. Ethanol productivity was different for each treatment (Fig. 5). After the 36th period of fermentation, the highest ethanol production was found in the $\mathrm{H}_{2} \mathrm{PO}_{4}^{-}$removal treatment, and $\mathrm{NH}_{4}^{+}$and $\mathrm{K}^{+}$removal treatment. Ethanol productivity in the $\mathrm{H}_{2} \mathrm{PO}_{4}^{-}$removal treatment was $3.95 \%(\mathrm{w} / \mathrm{v})$ after 24 hours of fermentation and $3.75 \%(\mathrm{w} / \mathrm{v})$ at 36 hours. On the other hand, the treatment with the lowest ethanol production was found to be $\mathrm{Fe}^{3+}$ removal treatment. Ethanol production was found to increase up to 24 hours of fermentation but not significantly after that.

\section{Discussion}

The effect of inorganic salts on biomass and bioethanol production from tobacco as herbaceous model plants was determined. Tobacco shoot had almost no effect on growth when cultured in a medium in which $\mathrm{Ca}^{+}, \mathrm{Fe}^{3+}$ and $\mathrm{Mg}^{2+}$ components were removed, but $\mathrm{H}_{2} \mathrm{PO}_{4}^{-}$and $\mathrm{NH}_{4}^{+}$removal treatment was good for growth. These results indicate that $\mathrm{H}_{2} \mathrm{PO}_{4}^{-}$and nitrogen sources $\left(\mathrm{NH}_{4}^{+}\right.$and $\left.\mathrm{NO}^{3-}\right)$ are the major inorganic salts important for the growth of tobacco. Phosphoric acid is well known as the main inorganic salt that increases cultivation and growth. Phosphorus is essential and is involved in the transfer of energy through ATP. It is also involved in root development and metabolic activity, especially in protein synthesis (Tanwar and Shaktawat 2003). In addition, the nitrogen $\mathrm{NO}^{3-}-\mathrm{N}$ and $\mathrm{NH}^{4+} \mathrm{N}$ forms in the soil are absorbed by plants and used for plant growth. Deficiency of nitrogen can impair plant growth and root growth (Mengel and Kirkby 1987). However, it can be seen that components such as $\mathrm{Ca}^{+}, \mathrm{Fe}^{3+}$ and $\mathrm{Mg}^{2+}$ are relatively less involved in growth than $\mathrm{N}, \mathrm{P}$, and $\mathrm{K}$.

The increase of a specific inorganic salt concentration can stimulate cell and tissue growth, but it can at the same time induce deficiencies of other nutrients by the dilution effect (Marschner 1995). Varying strength of inorganic salts of the basal media have been shown to markedly influence the micropropagation process in many plant species and suitable basal medium composition should be investigated for multiple shoots induction (Khalafalla et al. 2007).

Appearance of leaf was different based on each treatment. Leaf length had no significant effect except for the $\mathrm{H}_{2} \mathrm{PO}_{4}{ }^{-}$ removal medium. Leaf width also showed similar pattern to leaf length. These results mean that inorganic salts do not significantly affect leaf size. In general, it is known that the deficiency of inorganic salts reduces the size of leaves, which leads to a decrease in photosynthesis and eventually inhibits growth (Yeh et al. 2000). However, the results of this study were different from those of previous studies. The reason seems to be the short study period. Chlorophyll level in two species was affected based on inorganic salt treatments. The $\mathrm{Ca}^{2+}$ removal treatment had the highest average SPAD value. This result indicated that $\mathrm{Ca}^{2+}$ was not effect of inorganic salt on tobacco. The $\mathrm{H}_{2} \mathrm{PO}_{4}^{-}$and $\mathrm{NO}_{3}^{-}$removed treatment had the lowest average SPAD value. As these plants carry out lower levels of photosynthesis, they eventually accumulate less cellular material and less carbon skeleton (Borgatto et al. 2002). Root induction and growth also affected according to inorganic salts. It was found that $\mathrm{K}^{+}$and $\mathrm{Mg}^{2+}$ had a great influence on root development and growth. Niu et al. (2014) reported that primary root elongation and lateral root formation in Arabidopsis were not influenced by low $\mathrm{Mg}^{2+}$ but inhibited by high $\mathrm{Mg}^{2+}$ after one-week period. Damm et al. (2011) suggested that low $\mathrm{Mg}^{2+}$ availability together with high $\mathrm{K}^{+}$supply enhanced the root-shoot ratio prior to any visible sign of $\mathrm{Mg}^{2+}$ deficiency symptoms in rice leaves.

The $\mathrm{R} / \mathrm{S}$ ratio was also affected by the inorganic salt treatment. Under normal conditions, the ratio of root shoots in most trees ranges from 1:5 to 1:6 (Perry 1982). An increase 
in soil fertility is generally associated with a decrease in the $\mathrm{R} / \mathrm{S}$ ratio. That is, sprout growth gains more weight than root growth (Coutts and Philipson 1980). In the case of this study, the $\mathrm{R} / \mathrm{S}$ ratio was the highest at about 1.00 in the $\mathrm{K}^{+}$removed medium. $\mathrm{K}^{+}$is an essential nutrient for plant growth and development. It is the most abundant cations in plant cells and can make up up to $10 \%$ of the dry weight of the plant (Véry and Sentenac 2003).

The dry matter of shoot and roots of tobacco under inorganic salt removal medium differ significantly from control treatement. Yield reduction may be associated not only to the toxicity of a given inorganic salts, but also to the deficiency of other inorganic salts causing an ionic unbalance among nutrients (Marschner 1995).

The content of compounds in the plant was dependent on the inorganic salt. Low molecular weight extracts differed from treatments, and treatments with the highest extract content were in the order of $\mathrm{K}^{+}$and $\mathrm{H}_{2} \mathrm{PO}^{4-}$. The extract contents may contain non-structural components of biomass such as waxes, fats, tannins, sugars, some resins and coloring substances (Jung et al. 2010).

Inorganic salt treatment has been shown to play an important role in lignin biosynthesis. In particular, it is known that the lignin content is increased in plants cultured in $\mathrm{K}^{+}$ removal medium. Mandre (2002) reported a strong correlation between lignin and $\mathrm{Ca}$ and $\mathrm{K}$ concentrations in Picea needles and shoots. In addition, an increase in $\mathrm{K}^{+}$ concentration in wheat plants stimulated lignification (Miidla 1989). Hojatti and Maleki (1972) reported that $\mathrm{K}^{+}$increased the methionine content of wheat and that L-methionine could be a precursor to the methylation process during lignin formation.

Phloroglucinol staining has long been utilized for localizing lignins in plant tissue sections (Dean 1997). It stains lignins a purple coloration deriving from reactions of hydroxycinnamyl aldehyde end-groups that are systematically present in native lignin, albeit in low amounts (Jehan et al. 1994). Because Wiesner reagent gives only temporary visualization of color, images were recorded within $10 \mathrm{~min}$ of reagent application. Red staining with phloroglucinol indicates the presence of hydroxycin-namaldehydes in lignin. Phloroglucinol stains lignified cells red upon reaction with hydroxycinnamaldehyde groups present in the polymer Herbal products such as tobacco have already reported lignin confirmation. Franke (2000) confirmed lignin in poplar and tobacco transformed with the ferulate 5-hydroxylase gene involved in lignin biosynthesis by the Wiesner method, which is consistent with this study.

Inorganic salt treatment was found to have no significant effect on lignin content, but high concentration of inorganic salt treatment inhibited lignin biosynthesis in the poplar (Pitre et al. 2007).

Inorganic salts influenced the chemical composition of the tobacco plant cultured in vitro. The most ideal chemical composition for bioethanol production is lignin content is low, and the cellulose content is high. In this study, the lignin content was low in the plants cultured in the medium from which $\mathrm{K}^{+}$and $\mathrm{H}_{2} \mathrm{PO}_{4}^{-}$were removed.

On the other hand, the cellulose content was highest in the $\mathrm{NO}_{3}^{-}$and $\mathrm{H}_{2} \mathrm{PO}_{4}^{-}$removing treatments. The $\alpha$-cellulose level was found to be higher in $\mathrm{H}_{2} \mathrm{PO}_{4}^{-}$removed treatments than control.

The inorganic salt treatment also affected the cellulose content. In this study, the cellulose content of plants cultured in a medium excluding a nitrogen source was increased. A number of studies have reported that inorganic salts affect cellulose biosynthesis. Nitrogen in trees or soil is considered an important factor for both lignin and cellulose biosynthesis. For example, high $\mathrm{N}$ fertility increases the cellulose concentration in Pinus palustris Mill. seedlings, resulting in lower lignin concentrations (Tullus et al. 2009).

Ultrastructure of cellulose also affected on inorganic salts kinds. Fe-SEM graphs indicate that the microfibrils are separated from the initial connected structure and fully exposed. It would certainly increase the external surface area and the porosity of the biomass. More accessible external and internal surface area of $\alpha$-cellulose was attainable as binding site for cellulose, leading to the enhancement of enzymatic saccharification (Singh et al. 2009).

Inorganic salts were affected on enzymatic hydrolysis on in vitro cultured tobacco. In the treatment with the highest glycation rate, the concentration ratios of $79 \%$ and $78 \%$ of glucose were the highest after 24 hours of enzymatic hydrolysis for $\mathrm{NH}^{4+}$ removal treatment and $\mathrm{Mg}^{2+}$ removal tobacco treatment, respectively. Lignocellulosic biomass cannot be saccharified by enzymes to high yields without a pretreatment mainly because the lignin in plan cell walls forms a barrier against enzyme attack (Sewalt et al. 1997). The inorganic salt treatments would reduce the lignin content and crystallinity of the cellulose and increase the surface area. Factors that have been found to influence the hydrolysis of cellulose include the porosity of the waste (accessible surface area), cellulose fiber crystallinity, and lignin and hemicellulose content (McMillan 1994). As Marschner (1995) points out, potassium-deficient plants accumulate carbohydrates and soluble nitrogen compounds.

Yeast fermentation of raw sugars from tobacco plants 


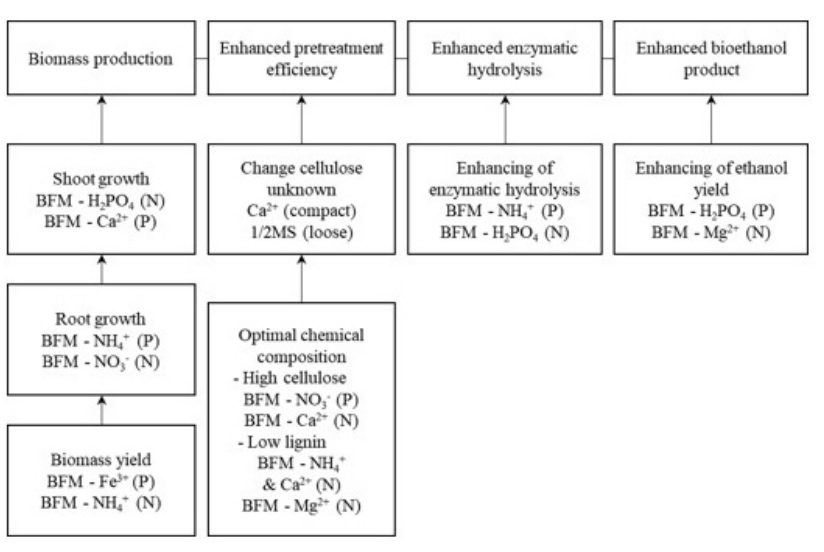

Fig. 6 Processing pathway for bioethanol production with cultured $N$. tabacum. Ethanol production involves biomass pretreatment, hydrolysis for monosaccharide production, and fermentation to produce ethanol. BPM; Bioenergy production medium, P: Positive; $\mathrm{N}$ : Negative

cultured in inorganic desalination medium has been shown to be effective. After 36 hours of fermentation, ethanol production was the highest in $\mathrm{H}_{2} \mathrm{PO}_{4}^{-}$removal treatment and $\mathrm{NH}_{4}{ }^{+}$and $\mathrm{K}^{+}$removal treatment. In particular, in this study, although the sample used for saccharification was not pretreated, the ethanol yield was 3.95\% (w/v) after 24 hours fermentation in $\mathrm{H}_{2} \mathrm{PO}_{4}^{-}$removal medium. After that, it is considered that bioethanol can be produced more economically if it is cultivated in a well-managed field of nutrition such as appropriate inorganic salts and proper pretreatment.

The ethanol productivity and fermentation time of this study were different from other previous studies. Studies on the production of bioethanol from most biomass (Spangler and Emert 1986) were fermented for $4 \sim 6$ days and up to 2. It is said that the yield of $3.95 \%(w / v)$ ethanol was shown. The difference from our study is that the material used in this study was less wood formation.

In conclusion, proper selection of inorganic salts can control biomass production, changes in chemical composition, enzymatic hydrolysis, and ethanol production. Currently, processes for the production of biomass and bioethanol include pretreatment, saccharification and fermentation (Fig. 6). The use of appropriate inorganic salts can affect the loosening of the structural integrity of the biomass components (lignin-hemicellulose-cellulose), accelerate hydrolysis and reduce the cost of producing precursors for bioethanol production. Understanding the relationship between nutritional requirements and growth stages allows growers to tailor their fertilization program based on the type of soil. These results can be used as basic data for the development of appropriate techniques for the control of various fertilizers for high biomass and bioethanol production in the future.

\section{Acknowledgements}

This research was supported by the support of the Forestry Science and Technology Research and Development Project (Forest Convergence Specialist Training Project, Project No. (2020186A00-2022-AA02).

\section{References}

Borgatto F, Dias CT, Amaral AFC, Melo M (2002) Calcium, potassium and magnesium treatment of Chrysanthemum morifolium cv. "Bi Time" and callogenesis in vitro. Sci agric 59:689-693

Carroll A, Somerville C (2009) Cellulosic biofuels. Annu Rev Plant Biol 60:165-182

Chandel AK, Garlapati VK, Singh AK, Antunes FAF, da Silva SS (2018) The path forward for lignocellulose biorefineries: bottlenecks, solutions, and perspective on commercialization. Bioresour Technol 264:370-381

Chapin FS (1991) Effects of multiple environmental stresses on nutrient availability and use. In: Mooney HA, Winner WE, Pell EJ (ed) Response of Plants to Multiple Stresses. Academic Press, pp 67-88

Coutts MP, Philipson JJ (1980) Mineral nutrition and tree root growth. In: Atkinson D, Jackson JE, Sharples RO, Waller WM (eds) Mineral nutrition of fruit trees. Butterworth, London, U.K. pp 123-136

Damm C, Mallembakam MR, Voronov A, Peukert W (2011) Production of filled hydrogels by mechanochemically induced polymerization. J Appl Polym Sci 120:799-807

Dean JFD (1997) Lignin analysis, In: Dashek WV (eds) Methods in plant biochemistry and molecular biology. CRC Press. pp 199-215

Dimitriou I, Rutz D (2015) Sustainable short rotation coppice - a handbook. WIP Renew-able Energies, Munich, Germany

Franke R, McMichael CM, Meyer K, Shirley AM, Cusumano JC, Chapple C (2000) Modified lignin in tobacco and poplar plantsover-expressing the arabidopsis gene encoding ferulate 5-hydroxylase. Plant J 22:223-234

Geiger H, Fuggerer H (1979) Über den chemismus der wiesnerreaktion auf lignin. Z Naturforschung 34:1471-1472

Hojatti SM, Maleki M (1972) Effect of potassium and nitrogen fertilization on lysine, methionine, and total protein contents of wheat grain, Triticum aestivum L. em. Thell.1. Agron J 65:46-48

Jehan H, Brown S, Marie D, Noin M, Prouteau M, Chriqui D (1994) Ontogenesis and ploidy level of plantlets regenerated from Populus trichocarpa deltoides cv. Hunnegem root, leaf 
and stem explants. J Plant Physiol 144:576-585

Jørgensen H, Vibe-Pedersen J, Larsen J, Felby C (2007) Liquefaction of lignocellulose at high-solids concentrations. Biotechnol Bioeng 96:862-870

Jung JY, Choi MS, Kim JS, Jeong MJ, Kim YW, Woon BT, Yeo JK, Shin HN, Goo YB, Rye KO, Karigar CS, Yang JK (2010) Enzymatic hydrolysate from non-pretreated biomass of yellow poplar (Liriodendron tulipifera) is an alternative resource for bioethanol production. Jour Korean For Soc 99:744-749

Kadam KL, Chin CY, Brown LW (2008) Flexible biorefinery for producing fermentation sugars, lignin and pulp from corn stover. J Ind Microbiol Biotechnol 35:331-341

Khalafalla MM, Elgaali EI, Ahmed MM (2007) In vitro multiple shoot regeneration from nodal explants of Vernonia amygdalina-an important medicinal plant. African Crop Science Conference Proceedings. 8:747-752

Krishna SH, Chowdary GV (2000) Optimization of simultaneous saccharification and fermentation for the production of ethanol from biomass. J Agric Food Chem 48:1971-1976

Kumar AK, Sharma S (2017) Recent updates on different methods of pretreatment of lignocellulosic feedstocks: a review. Bioresour Bioprocess. 4:7. DOI 10.1186/s4064 3-017-0137-9

Mandre M (2002) Relationships between lignin and nutrients in Picea abies L. under alkaline air pollution. Water Air Soil Pollut 133:363-379

Marschner H (1995) Mineral nutrition of higher plants (Mengel, K. and Kirkby). Academic Press. pp 889

McMillan JD (1994) Pretreatment of lignocellulosic biomass. In: Himmel ME, Baker JO, Overend RP (eds) Enzymatic conversion of biomass for fuels production. American Chemical Society. pp 292-324

Mengel K, Kirkby EA (1987) Nitrogen. In: Mengel K, Kirby EA (ed) Principles of plant nutrition 4th edition. International Potash Institute, Bern. pp 347-384

Miidla H (1989) Biochemistry of lignin formation. In: Padu E (eds) The formation of lignin in wheat plants and its connection with mineral nutrition, Acta Comm Univ, Tartuensis, 845, Tartu, pp 11-23

Murashige T, Skoog F (1962) A revised medium for rapid growth and bioassays with tobacco tissue culture. Physiologia Plantarum 15:473-497

National Renewable Energy Laboratory (NREL) (1996) Chemical Analysis and

Niu Y, Jin G, Zhang YS (2014) Root development under control of magnesium availability. Plant Signal Behav. DOI 10.4161/ psb. 29720

Perry TO (1982) The ecology of tree roots and the practical significance thereof. J Arboric 8:197-211
Pitre FE, Pollet B, Lafarguette F, Cooke JEK, MacKay JJ, Lapierre C (2007) Effects of increased nitrogen supply on the lignification of poplar wood. J Agric Food Chem 55: 10306-10314

Sewalt VJH, Glasser WG, Beauchemin KA (1997) Lignin impact on fiber degradation. 3. reversal of inhibition of enzymatic hydrolysis by chemical modification of lignin and by additives. J Agric Food chem 45:1823-1828

Simmons BA, Loque D, Ralph J (2010) Advances in modifying lignin for enhanced biofuel production. Curr Opin Plant Biol 13:313-320

Singh D, Chen S (2008) The white-rot fungus Phanerochaete chrysosporium: conditions for the production of lignin-degrading enzymes. Appl Microbiol Biotechnol 81:399-417

Singh S, Simmons BA, Vogel KP (2009) Visualization of biomass solubilization and cellulose regeneration during ionic liquid pretreatment of switchgrass. Biotechnol Bioeng 104:68-75

Sluiter A, Hames B, Ruiz-Peinado R, Scarlata C, Sluiter WJ, Templaton D, Crocker A, Sluiter MD (2010) Determination of structural carbohydrates and lignin in biomass, Technical Report NREL/TP-510-42618, National Renewable Energy Laboratory, Golden, CO, USA

Spangler DJ, Emert GH (1986) Simultaneous saccharification and fermentation with Zymomonas mobilis. Biotechnol Bioeng 28:115-118

Tanwar SPS, Shaktawat MS (2003) Influence of phosphorus sources, levels and solubilizers on yield, quality and nutrient up-take of soybean (Glycine max) -Wheat (Triticum aestivum) cropping system in southern Rajasthan. Indian J Agric Sci $73: 3-7$

Testing Laboratory Analytical Procedures : LAP-002. National Renewable Energy Laboratory, Golden, CO, USA.

Tillman DA (2000) Biomass co-firing: The technology, the experience, the combustion consequences. Biomass Bioenergy 19:365-384

Tullus A, Mandre M, Soo T, Tullus H (2009) Relationships between cellulose, lignin and nutrients in the stemwood of hybrid aspen in Estonian plantations. Cell Chem Technol 44:101-109

Véry AA, Sentenac H(2003) Molecular mechanisms and regulation of $\mathrm{K}^{+}$transport in higher plants. Annu Rev plant Biol 54:575-603

Yeh DM, Lin L, Wright CJ (2000) Effects of mineral nutrient deficiencies on leaf development, visual symptoms and shoot-root ratio of Spathiphyllum. Sci Hortic 86:223-233

Zoghlami A, Paës G(2019) Lignocellulosic biomass: understanding recalcitrance and predicting hydrolysis. Front Chem 7: 874 DOI 10.3389/fchem.2019.00874 